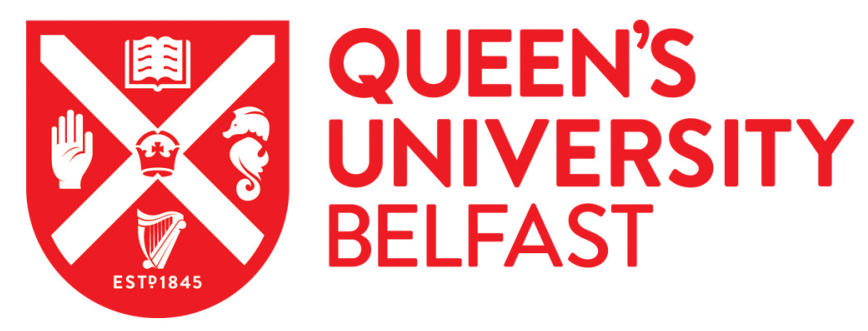

\title{
Plant community assembly at small scales: spatial versus environmental factors in a central European grassland
}

Horn, S., Hempel, S., Ristow, M., Rillig, M. C., Kowarik, I., \& Caruso, T. (2015). Plant community assembly at small scales: spatial versus environmental factors in a central European grassland. Acta Oecologica, 63, 56-62. https://doi.org/10.1016/j.actao.2015.01.004

\section{Published in:}

Acta Oecologica

Document Version:

Peer reviewed version

Queen's University Belfast - Research Portal:

Link to publication record in Queen's University Belfast Research Portal

Publisher rights

Copyright 2015 Elsevier

This is the author's version of a work that was accepted for publication in Acta Oecologica. Changes resulting from the publishing process, such as peer review, editing, corrections, structural formatting, and other quality control mechanisms may not be reflected in this document. Changes may have been made to this work since it was submitted for publication. A definitive version was subsequently published in Acta Oecologica

, [VOL 63 (February 2015)] doi:10.1016/j.actao.2015.01.004

General rights

Copyright for the publications made accessible via the Queen's University Belfast Research Portal is retained by the author(s) and / or other copyright owners and it is a condition of accessing these publications that users recognise and abide by the legal requirements associated with these rights.

Take down policy

The Research Portal is Queen's institutional repository that provides access to Queen's research output. Every effort has been made to ensure that content in the Research Portal does not infringe any person's rights, or applicable UK laws. If you discover content in the Research Portal that you believe breaches copyright or violates any law, please contact openaccess@qub.ac.uk. 


\section{Plant community assembly at small scales: spatial versus environmental}

2 factors in a central European grassland

3

4 Sebastian Horn $^{* 1,4}$, Stefan Hempel ${ }^{1,4}$, Michael Ristow ${ }^{2,4}$, Matthias C. Rillig ${ }^{1,4}$, Ingo Kowarik ${ }^{3,4}$,

5 Tancredi Caruso ${ }^{1,5}$

6

71 Institut für Biologie - Ökologie der Pflanzen, Freie Universität Berlin, Altensteinstr. 6, 14195

8 Berlin, Germany

92 Institut für Biochemie und Biologie - Vegetationsökologie und Naturschutz, Universität 10 Potsdam, Maulbeerallee 2, 14469 Potsdam, Germany

113 Institut für Ökologie, FG Ökosystemkunde, Technische Universität Berlin, Rothenburgstr.

12 12, 12165 Berlin, Germany

134 Berlin-Brandenburg Institute of Advanced Biodiversity Research (BBIB), 14195 Berlin, 14 Germany

155 School of Biological Sciences, Queen’s University Belfast. Medical Biology Centre, 97 Lisburn Road, Belfast BT9 7BL, Northern Ireland, UK

* Corresponding author, Tel.: +49 30838 53145. E-mail address: sebastian.horn@fu-berlin.de 19

Keywords: Assembly pattern; Dispersal limitation; Festuca brevipila; Niche partitioning; Null model; Plant community ecology; Variance partitioning 


\section{Abstract}

Dispersal limitation and environmental conditions are crucial drivers of plant species distribution and establishment. As these factors operate at different spatial scales, we asked: Do the environmental factors known to determine community assembly at broad scales operate at fine scales (few meters)? How much do these factors account for community variation at fine scales? In which way do biotic and abiotic interactions drive changes in species composition? We surveyed the plant community within a dry grassland along a very steep gradient of soil characteristics like $\mathrm{pH}$ and nutrients. We used a spatially explicit sampling design, based on three replicated macroplots of 15x15, 12x12 and 12x12 meters in extent. Soil samples were taken to quantify several soil properties (carbon, nitrogen, plant available phosphorus, $\mathrm{pH}$, water content and dehydrogenase activity as a proxy for overall microbial activity). We performed variance partitioning to assess the effect of these variables on plant composition and statistically controlled for spatial autocorrelation via eigenvector mapping. We also applied null model analysis to test for non-random patterns in species co-occurrence using randomization schemes that account for patterns expected under species interactions.

At a fine spatial scale, environmental factors explained $18 \%$ of variation when controlling for spatial autocorrelation in the distribution of plant species, whereas purely spatial processes accounted for $14 \%$ variation. Null model analysis showed that species spatially segregated in a non-random way and these spatial patterns could be due to a combination of environmental filtering and biotic interactions. Our grassland study suggests that environmental factors found to be directly relevant in broad scale studies are present also at small scales, but are supplemented by spatial processes and more direct interactions like competition. 


\section{Introduction}

Plant community assembly is significantly driven by filtering processes on several scales, like competition (Aarssen, 1989), dispersal limitation (Ai et al., 2012) and environmental conditions (Latimer and Jacobs, 2012). Understanding the processes involved in the assembly of communities is considered one of the most important challenges in ecology today (HilleRisLambers et al., 2012; O’Neill, 1989; Turner and O’Neill, 1995). While the understanding of community assembly has advanced significantly within the last 50 years, ecologists still lack precise insight on how the interplay of organisms and their environment determines the structure of natural communities (Götzenberger et al., 2012; Naaf and Wulf, 2012).

One common idea in ecology about the assembly of a diverse community involves filtering by the environment and interactions of organisms that establish local populations. This led to the niche-partitioning concept (Leibold, 1995; Silva and Batalha, 2011), where assemblages of species are viewed as having different tolerances to the abiotic environment and differing abilities to exploit resources. With the rise of neutral theory (Hubbell, 2001; Rosindell et al., 2012), the debate on the processes influencing biodiversity was reinvigorated and the search for a unified theory has dominated the field (Adler et al., 2007). It has been suggested that the combination of investigating both local and short-term mechanisms as well as regional processes occurring over longer timescales may be crucial for the complete understanding of ecosystem assembly and function (HilleRisLambers et al., 2012).

Grasslands cover one fourth of the Earth's land surface and harbour the majority of annual plant diversity (Shantz, 1954). A significant amount of studies on grassland ecosystems are focused on the influence of soil characteristics on plant community composition (Wellstein et al., 2007), which, together with water, wind and sunlight, represents the bulk of abiotic influences on a plant community (Callaway, 1997; Parfitt et al., 2010). Soil characteristics can be strong predictors of plant community composition (Gough et al., 2000; Tilman and Olff, 1991), although the scale of the studies influences the predictive power of soil parameters like $\mathrm{pH}$, carbon, nitrogen or phosphorus content (Sebastiá, 2004). But not only abiotic factors are influenced by the scale of a study; positive and negative species-species associations can occur at small scales and disappear with increasing scale (Wiegand et al., 2012).

In this study we aimed at increasing the understanding of scale-dependence in community patterns by using a metacommunity approach to analyse the plant community composition of a semi-natural grassland (Leibold et al., 2004). While a lot of studies on grasslands are trying to 
approach community composition mechanisms by inferring local interactions via the observation of larger-scale composition (Eckhardt et al., 1996; Thomas and Palmer, 2007; Toogood et al., 2008), we were aiming at understanding these processes by looking for patterns of species composition that could be either deterministically or stochastically structured while choosing the smallest local community possible: a single focal plant and its direct rhizosphere interaction partners, making the community unit as small as possible. Other small-scale studies have dealt with similar grain sizes like ours (Chu et al., 2007; Reitalu et al., 2009; Turtureanu et al., 2013), however, they do not approach single plants with their rhizosphere environment or combine small grain and extent. We consider everything beyond the single plant rhizosphere environment a metacommunity, implicitly embodying the idea of interactions of plants with the environment and each other.

Our study area offers unique possibilities of studying steep environmental gradients within only a few meters in a very species-rich grassland which also harbours one highly abundant plant species, enabling us to observe potential environmental filtering as well as spatial processes and biotic interactions in a spatially well-defined small-scale area. We selected this plant species, namely Festuca brevipila R. TRACEY (Aiken and Darbyshire, 1990; Klotz et al., 2002), as our focal plant to be able to target the whole gradient of environmental conditions which our study area offers, and still be able to standardize the metacommunity perspective on one species. We used patterns of co-variation among plant species, environmental and spatial variables derived from a neighbour matrix to answer the following questions: i) Do the environmental factors, like soil characteristics, that are known to determine community assembly at broad scales also operate at fine scales (1-15 meters) and how much do these factors account for community variation at fine scales? ii) In which way do biotic and abiotic factors drive changes in species composition? Our questions involve the disentanglement of patterns at various small scales, which calls for tools able to quantify the contributions of environmental, spatial patterns and their shared effect. Therefore state-of-the-art multivariate analysis will be applied (Borcard et al., 1992; Dray et al., 2006). Given the small scale at which we conduct our study, we are able to compare the importance of the environment found on larger scales with the processes shaping our analyzed community that are strongly spatially structured. Large-scale environmental effects that determine plant community structure in a range from a few to several hundred kilometres, include climatic gradients (Ludewig et al., 2014), altitudinal changes (Krömer et al., 2013) or differences in soil biogeochemistry (Khan et al., 2013). It might be that due to the small scale of our study area the environment will only have a minor influence despite the 
114 strong gradient since biotic interactions could be more influential and random effects or neutral 115 dynamics might overlay species sorting effects.

116 


\subsection{Data collection}

120

The grassland studied is situated in a natural reserve (Mallnow Lebus, Brandenburg, Germany, $52^{\circ} 27.778^{\prime} \mathrm{N}, 14^{\circ} 29.349^{\prime} \mathrm{E}$ ). The region is influenced by sub-continental climate with a mean annual precipitation of below $500 \mathrm{~mm}$ (Ristow et al., 2011) and the area is managed by sheep grazing twice a year. The sampling strategy was based on a hierarchical nesting of macroplots and plots, and was done at the end of June 2011 to minimize influences by spring ephemerals. Three macroplots of 15 x 15, 12 x 12 and 12 x 12 meters, respectively (Fig. 1), were located on the slopes of mostly undisturbed hills in an area of about five hectares. Grazing was very limited on our macroplots due to the strong slope and only minor traces of sheep trails were found. We ensured that all macroplots were part of two closely related grassland communities found in Mallnow, namely Sileno otitae-Festucetum-brevipilae Libbert 1933 corr. Kartzert \& Dengler 1999 and Festuco psammophilae-Koelerietum glaucae Klika 1931. Our macroplots were comparable concerning vegetation and soil related factors like distance from trees, stone content or depth of A-horizon, as well as slope and sun exposure, and therefore can be considered a replicated design. The uphill-downhill axes of the macroplots are characterized by a steep textural gradient from highly sandy (downhill macroplot) to sandy-loamy (uphill macroplot) soils. Preliminary analyses revealed that this gradient causes gradients in many other soil parameters, namely $\mathrm{pH}$, carbon, nitrogen and plant available phosphorus. Each macroplot was divided into $3 \times 3 \mathrm{~m}$ plots (Fig. 1). From each macroplot the vegetation of the four corner plots (top left, top right, bottom left, bottom right) was sampled: For the measurement of soil properties one soil core per plant was taken atop of five randomly chosen $F$. brevipila plants per plot, creating 60 samples in total. In a radius of $15 \mathrm{~cm}$ around the chosen F. brevipila plant, the local plant community was assessed visually as presence or absence of plant species. This sampling unit represents our main community unit and below we refer to it as "sample”. With regard to the smallest sampling unit ("sample”), the $15 \mathrm{~cm}$ radius ensures that interactions within the rhizosphere of $F$. brevipila plants were captured. We preferred this method to a totally random location of the sampling units (i.e. not having a focal species) for the following mutually reinforcing reasons: a random location would have been strongly biased towards $F$. brevipila in a non-controlled way because F. brevipila is by far the most abundant species in the area (in some case the species can cover up to $70 \%$ of one plot); by controlling for this critical source of certain bias, we could minimise possible very small scale environmental heterogeneity that could confound the interpretation of co-occurrence analysis based on null 
models (see methods below) and the comparison between null models and multivariate analyses based on RDA; the plant assemblage can be objectively defined at a biologically meaningful small scale (i.e. rhizosphere) as the neighbourhood community of the dominant species. This makes the community unit highly replicable: the average composition of this particular but representative assemblage can be assessed throughout plots and macroplots as a function of changes in the environment and the effects of the environments on how species interact within this assemblage. By having a focal species and defining the assemblage as a function of it, we lost some degree of generality but it is also true that our focal species and the genus to which it belongs (Festuca) is one of the most abundant if not the most abundant and widespread species in dry grasslands overall the world. Thus, we could compare total plant species richness of each plot with the species richness found in the proximity of each of the five randomly sampled $F$. brevipila plant per plot. The corner plots were chosen to use the maximum of the environmental gradient along one direction (the downhill-uphill axis) and a minimum of it in the direction orthogonal to the environmental gradient while keeping the spatial distances between plots equal. Thus, the three macroplots represent three spatial replicates while the environmental gradient is replicated twice within each macroplot.

Each soil core was thoroughly homogenized and representatively subsampled for the different analyses. Soil water content was measured as the weight difference between fresh and ovendried soil cores. Soil carbon and nitrogen analysis was performed on a EuroEA 3000 Elemental Analyser (EuroVector, Milano, Spain) with a TDC detector using 25 mg of pulverized soil per core. Soil pH was measured in $10 \mathrm{mM} \mathrm{CaCl}_{2}$ solution (van Lierop and Mackenzie, 1977) using 3 grams of soil per core. Plant available phosphorus was characterized following the CALmethod (Sparks, 1996) using 1 gram of soil per core. Dehydrogenase assays were conducted according to Rossel (1997), using 1 gram of soil per core. The $\mathrm{pH}$, carbon, nitrogen and phosphorus content data were used to create maps based on ordinary kriging to visualize environmental gradients within the macroplots (Fig. S1). This was used to elucidate the actual presence and orientation of a gradient.

\subsection{Statistical analysis}

Normality was checked with the Kolmogorov-Smirnov test and variables were transformed to meet the requirements of parametric analysis when necessary. The subsequent analysis of patterns in community structure was conducted in R 2.15.2 (2013), with functions from the vegan (Oksanen et al., 2012) and the SPACEMAKER (Dray, 2011) package. Source code from the analysis in $\mathrm{R}$ is provided in the supporting information. We created a presence/absence matrix 
for the plant species recorded in each sample, containing 60 samples and 68 identified plant species. Environmental factors for each sample were summarized in a matrix containing seven columns for the factors and 59 rows for the samples. Eventually, one row had to be omitted from all matrices since one soil core was lost prior to analysis. All the species matrices including the subsets used were stripped from zero-occurrences spots and species, respectively, prior to the subsequent analysis. For completeness reasons, the whole species matrix is included in the supplementary information. Multivariate analysis was done on a per-sample basis, while the null model analysis was conducted on various subsets of the whole data matrix (see below). The species presence / absence matrix was Hellinger transformed and subjected to a multivariate analysis to disentangle spatial and environmental factors influencing community variation (Legendre and Legendre, 1998). At first a canonical correspondence analysis (CCA) was conducted with the coordinates of the samples as constraints in order to remove linear spatial patterns. The remaining spatial patterns of the detrended community data were summarized, together with the geographical distance matrix of the samples, in the Moran eigenvector mapping matrix (MEM) that best accounted for autocorrelation (Dray et al., 2006). The final spatial matrix used for analysis then contained both the MEMs and the linear trends. Spatial autocorrelation represents the predictability of a locally observed response value by response variables observed in the surrounding area (Legendre, 1993). The MEM is calculated by multiplying a connectivity binary matrix with a weighting matrix. The connectivity matrix represents a graph in which samples are connected as networks while the weighting matrix is used to quantify the sample dissimilarity by weighting each link of the network (Caruso et al., 2012). In order to test multiple spatial patterns, the connectivity and/or weighting algorithms were modified and the best model was selected following the Akaike Information Criterion AIC (Akaike, 1973). Thus, the best linear combination of eigenvectors was chosen so the correlation with the data would be maximal and the AIC values would be minimal (Dray et al., 2006). An extracted eigenvector summarizes spatial patterns at a given scale; therefore the cumulative matrix of eigenvectors can describe several spatial scales. This matrix then can be used in multivariate regression approaches to predict spatial patterns (Dray et al., 2006). The eigenvector method we utilised is able to detect patterns down to a scale of $1 \mathrm{~m}$, which equals roughly twice the average distance between our samples. We used redundancy analysis (RDA) and variance partitioning to resolve the contribution of environmental and spatial factors to the total variance (Legendre and Legendre, 1998). The community matrix was used as response matrix and measured environmental factors like carbon, nitrogen or $\mathrm{pH}$, plus the MEM vectors representing spatial autocorrelation were used as explanatory factors for the response matrix. 
Since plants tend to respond more strongly to a change in nutrient availability when the nutrient is scarce than when it is abundant, we followed suggestions by Jones et al. (2008) and tried to transform the environmental data by taking their natural logarithm and generate a polynominal environmental dataset prior to variance partitioning. However, this did not change the results compared to untransformed data, we therefore only report results from the latter dataset. Variance partitioning is a tool to quantify the unique contribution of these two components plus the spatial patterning shared by the environmental data (Borcard et al., 1992). Multivariate variances were visualized using principal coordinate analysis (Anderson and Willis, 2003). Each of the variance partitions was subjected to a constrained redundancy analysis and subsequent statistical test at $\mathrm{P}<0.05$, based on permutation (Oksanen et al., 2012). We applied automatic stepwise model building for constrained ordination methods using the ordistep function (Blanchet et al., 2008) with forward and backwards selection to include important environmental variables only and calculate their respective P-values.

Since mosses and lichens can affect seedling establishment of higher plants (Soudzilovskaia et al., 2011), their cover was considered as an additional environmental factor; however, this did not increase the variance explained by the environment (data not shown). Lichens and mosses were thus excluded from further analysis albeit their inclusion slightly increased the explained variation of the spatial component.

Since variance partitioning quantifies variation in our community data but does not indicate a positive or negative trend of the species coexistence necessary to judge the role of biotic interactions, we applied a null model analysis done in PAIRS (Ulrich, 2008). In our null model analysis the C-score index was used to compute values of co-occurrence for the given set of presence/absence data. Since the C-score does not require perfect checkerboard distributions and has a low susceptibility to type II errors, it seemed best suited for our purpose (Gotelli, 2000). The input matrix was randomized following the suggestions of Gotelli (2000) to minimize type I errors and test for patterns of co-occurrence expected under non-random assembly processes and interacting species. The algorithm used fixed sums of rows and sums of columns and applied the Random Knight's Tour approach for shuffling the matrix. Retaining the row and column totals preserves differences in species richness among sites and differences in occurrence frequencies among species, therefore representing a conservative approach when testing for patterns in species composition. We applied a nestedness analysis using the matrix temperature method (Atmar and Patterson, 1993). Since the results indicated a strongly nested community, the data set was split up according to geographic orientation, and in addition to the whole community matrix, the subsets of the top, bottom, left and right plots were each subjected 
253 to a null model analysis. The top and bottom subsets represent the spatial distance since the 254 gradient in each subset is minimized. The left and right subsets represent the whole gradient 255 together with the spatial component (see Fig. 1) In addition, we included a subset of the diagonal 256 patterns (that is, the top left plus the bottom right plots and the top right plus the bottom left 257 plots) in order to account for potential tilting of the gradient orientation (compare Fig. 2).

258 The null hypothesis was considered rejected when the observed C-Score was significantly 259 different from the average simulated C-Scores $(\mathrm{P}<0.05)$. A C-score lower than the simulated 260 average represents an aggregated community, while a higher score represents a segregating 261 community. Standardized effect sizes were used to compare results meaningfully and calculate 262 probability values. The effect size is calculated as (observed C-score - simulated C-score) / 263 (standard deviation of simulated C-score). Negative standardized effect sizes indicate that the 264 observed index was less than the mean of the simulated indices while positive values indicate 265 that the observed index was greater than the mean of the simulated indices (Gotelli and 266 Entsminger, 2012). 


\section{Results}

270

271

272

273

\subsection{Sampling}

We detected a total of 68 herb and grass species plus five different species of mosses and lichens in the survey of the entire plots, outlining the high abundance found in our sample region. Out of these herb and grass species, 47 species were found inside the $15 \mathrm{~cm}$ radius environment of sampled Festuca brevipila plants (see Table S1). Species not found in the $15 \mathrm{~cm}$ radius around samples were excluded from the species matrix prior to analysis so no zero-occurrences were present in the matrices subsequently used. The majority of plant cover was attributed to the grasses Festuca brevipila and F. psammophila, accounting together for up to $70 \%$ of the plant canopy in a plot. Other abundant plants were Arrhenatherum elatius, Carex humilis and Rumex acetosella, which are all common representatives of sunny-dry nutrient poor grassland habitats (Hensen, 1997).

All plots showed steep gradients in $\mathrm{pH}$, carbon and nitrogen content (Fig. 1, Table S2), with macroplot 3 being generally richer in nutrients than macroplots 1 and 2. Plant available phosphorus content was poor in all three macroplots, ranging from $8.7 \mathrm{mg} / \mathrm{kg}$ soil to 42.2 $\mathrm{mg} / \mathrm{kg}$. Soil C to N ratios ranged between 11:1 and 23:1. Measured $\mathrm{pH}$ ranged from 3.7 to 7.6, encompassing four orders of magnitude in $\mathrm{pH}$ change. Macroplot 1 represented almost the whole $\mathrm{pH}$ range, while macroplot 2 was more acidic and macroplot 3 more alkaline than macroplot 1. Distances between samples in the plots ranged from 0.32 meters to 2.6 meters, with an average of 1.56 metres.

\subsection{Variance partitioning}

From the different models tested for the MEMs, the "Nearest Neighbour" approach for calculating the connectivity matrix with a concave-down weighting function yielded the lowest AIC and was subsequently used for calculating the eigenvector maps. The spatial component of the variation could be described by five low-rank MEMs and one high-ranking MEM, pointing out that in our community spatial influences are predominantly small-scaled, that is to say there is more significant spatial structure within plots and macroplots than between macroplots. The variance partition attributed $17.9 \%$ of the community variation to spatially independent environmental variables, from which carbon, nitrogen and $\mathrm{pH}$ were significant at $\mathrm{P}<0.05$ (Table 1). The spatial component represented by the MEMs accounted for $14.5 \%$ of the community variation and was highly significant (Table 1), while the spatially structured 
environmental component (i.e. shared variation between spatial and environmental variables) accounted for $4.7 \%$ of the variation. Roughly $63 \%$ of variance remained unexplained (Table 1 ). When we tested for the effect of environmental variables ignoring spatial autocorrelation (Table 1, second column), all tested environmental factors except water content and microbial activity were significant, indicating that spatial structure in the environment could drive some of the spatial changes observed in the plant community (Table 1, compare first two columns). The linear effect of the linear spatial coordinates alone accounted for 3.6\% of total variation.

\subsection{Null model analysis}

The null model analysis revealed that the C-score was consistently higher in the sampled communities than in the random ones, making the matrix overall segregated. This was also true for every subset of the metacommunity we tested. This clearly shows that species associate nonrandomly (Table 2). PAIRS reported a list of significant plant pair interactions, which we used to examine types of interactions between plants. When we tested the subsets of the community matrix, we noticed that the difference in effect size was higher for the left and right subset (i.e. along the environmental gradient) than for the top and bottom ones (i.e. orthogonal to the environmental gradient, Table 2). The effect size represents a measure of segregation strength, with larger effects sizes indicating more strongly segregating communities. The results indicate that the spatially structured environment is a bigger segregating factor than the environmental gradient alone, which is consistent with our variance partition results. In order to check for biases in the pooling of the subsets, we also compared the effect sizes of the three macroplots plus the possible two-macroplot-combinations (1 and 2; 2 and 3; 1 and 3), however, the effect sizes were comparable in all three subsets (Table 2). Since some of the individual gradients were not perfectly aligned with the sides of the macroplots, we also examined effect sizes of cross-plot subsets (that is, all plots in the southwest - northeast axis and all plots in the southeast - northwest axis). We noticed that the gradient axis oriented towards the $\mathrm{pH}$ causes a less segregating community than the axis oriented towards carbon and nitrogen (Fig. 2, Table S2). Mosses and lichens were not included in the null model analysis; however, including them did not change the result (data not shown). 
4.1. Do the environmental factors that are known to determine community assembly at broad scales operate at fine scales?

Given the steep gradients and the high species richness we found in our study area, we initially expected that environmental filtering account for significantly more of community variance than the spatial component. We found that the environment is on par with spatial processes similar to the results found in other ecosystems (Li et al., 2011). The fact that environmental filtering play a significant part in shaping plant communities is a common idea in community ecology (Medinski et al., 2010; Olff and Ritchie, 1998; Payne et al., 2011; Silva and Batalha, 2010; Tilman and Olff, 1991; Wellstein et al., 2007). We included the environmental factors that are generally considered important drivers of plant growth and distribution and that should cover the majority of abiotic influences (Bardgett, 2005). Even so, we lack a complete analysis of the micronutrients like $\mathrm{Mg}$, Fe or $\mathrm{Zn}$, and in general any aboveground environmental data like temperature, rainfall distribution or wind strength (even though these macroscopic factors definitely operate at scales much broader than those of our study). This might obscure some patterns currently not attributed to the environmental factors. Nonetheless, given the influence of key parameters like $\mathrm{pH}$ or phosphorus and the conservative analysis approach, it is unlikely that measuring more environmental variables would significantly increase the amount of variation accounted for by the environment. In fact, variables such as micronutrients generally correlate well with the general parameters (e.g., $\mathrm{C}$ and $\mathrm{pH}$ ) we have measured. Since every environmental variable was spatially structured in our study area, it is possible that a significant influence from an unmeasured variable would be reflected in the spatial eigenvectors and could therefore be accounted for indirectly. Also, given the variables we measured, it is unlikely that we missed out major environmental predictors of plant communities. Next to the environmental part of the variation, a smaller fraction of variation was accounted for by the spatially structured environment component, which suggests that the environment might exert its effect in a spatially structured fashion (see below). The processes behind patterns found when analysing communities oriented along the different environmental gradients via null models may account for a significant part of the variation that remained unexplained after multivariate analysis. Variance partitioning revealed that roughly half of the explained variance in species composition is due to the spatial position of the plant species in our sampled macroplots, regardless of environmental variation (Table 1). The permutation tests pointed out that the spatial structure of the environment can be a major determinant, given the significance of the 
environmental terms with and without spatial autocorrelation corrected (Table 1). This suggests that the prevalent environmental filtering could determine changes in species composition via its own spatial structure and/or by interacting with other processes, especially biotic interactions which are expressed by stabilizing niche differences (Hall et al., 2003). The scale of our study is so small that we can rule out dispersal limitation or considered it a very minor source of spatial variation. Thus, we have a spatially structured effect of the environment, which could also be due to biotic interactions mediated by the environment, plus much spatial variation that neither the environment nor dispersal limitation can account for.

The remaining proportion of unexplained variation in community composition is likely to represent either random variation or variation related to unmeasured variables that are not spatially auto-correlated at the scales considered by our sampling design and MEM method (Table 1). It might be possible that processes in the sub-meter range may be responsible for parts of the unexplained variation; however, our analysis was designed to capture processes taking place between our community sampling units on a scale of more than one meter.

taing place beween our communty sanpling units on a scale of more than one met.

\subsection{In which way do biotic and abiotic factors drive changes in species composition?}

Null model analysis confirmed that changes in species between sampling spots are not random. We found that the segregation of species is higher in our studied area than expected by chance (Table 2).

The effect sizes of different subsets we analysed were all positive, indicating that the segregating effects are ubiquitous and do not necessarily correlate with spatial changes in the environment, a result consistent with the multivariate results discussed two paragraphs above. Given that it is a fair assumption that dispersal limitation does not play a significant role in our study system, we can thus assume that negative biotic interactions (consistent with segregation) can act as a structuring factor alongside the environmental filtering processes in our system, alongside other potential effects attributed to small-scale environmental heterogeneity too small to be addressed by the design of our study. We noticed that the effect sizes differed noticeably in certain subsets of our data. These differences can be linked to some characteristics of the gradient in our plots, thereby suggesting a potential effect of environmental gradients exerted via biotic interactions. For example, we see that the plants in the top plots are segregating more strongly, thus we can infer that biotic processes like competitive exclusion should be more prevalent there. In fact, the upper part of the hills was less sandy and more densely populated 
with generally larger plants, which implies more competition for space or light. It has also been suggested that positive relationships between species are related to stressful conditions and negative relationships to productive environments (Callaway et al., 2002; Walker and Chapin, 1987), which is in consent with our observations given that the upper hill part of our sampling areas is indeed more productive due to higher resource availability (like water, nutrients and sunlight).

Complex interactions among conflicting processes such as competition for space, optimization of space utilization or demand for similar resources can facilitate exclusion (Sebastiá, 2004). We found a large difference in effect size and hence segregation when comparing the left and right subsets of the macroplots, which cannot be attributed just to environmental gradients, but also to patchy processes which remain to be investigated. In part, patterns of variation in the effect size of segregation seem to correlate with some environmental heterogeneity observed within macroplots (Table 2).

We never detected aggregation in any heterogeneous subset of the community matrix, which suggests that environmental filtering can take place mostly via niche partitioning, although care must be taken when inferring these processes from co-occurrence patterns. Given the small scale of our sampling design, we are not likely to find local coexistence, therefore any niche partitioning will be observed as segregation of species. The scale of observation may influence, how positive and negative interactions are related to biodiversity (Gotelli et al., 2010).

\section{Conclusion}

Overall, our data supports the hypothesis that at small scales steep environmental gradients share equal importance in structuring the plant assemblage dominated by Festuca brevipila with either spatially structured environmental effects or species spatial segregation due to negative interactions or a combination of these two factors. Small scale and high resolution sampling design will in the future allow teasing apart these two factors and scaling up their effects. 


\section{Acknowledgements}

428 We would like to thank the Deutsche Forschungsgemeinschaft (DFG) for generous financial 429 support. 
Aarssen, L.W., 1989. Competitive Ability and Species Coexistence - a Plants-Eye View. Oikos 56, 386-

Adler, P.B., HilleRisLambers, J., Levine, J.M., 2007. A niche for neutrality. Ecol Lett 10, 95-104.

Ai, D., Desjardins-Proulx, P., Chu, C.J., Wang, G., 2012. Immigration, Local Dispersal Limitation, and the Repeatability of Community Composition under Neutral and Niche Dynamics. PLoS ONE 7.

Aiken, S.G., Darbyshire, S.J., 1990. Fescue grasses of Canada. Canadian Government Publishing Centre. Akaike, H., 1973. Information theory and an extension of the maximum likelihood principle, in: Petrov, B.N., Csaki, B.F. (Eds.), Second International Symposium on Information Theory. Academiai Kiado, Budapest, pp. 267-281.

Anderson, M.J., Willis, T.J., 2003. Canonical analysis of principal coordinates: A useful method of constrained ordination for ecology. Ecology 84, 511-525.

Atmar, W., Patterson, B.D., 1993. The Measure of Order and Disorder in the Distribution of Species in Fragmented Habitat. Oecologia 96, 373-382.

Bardgett, R.D., 2005. The biology of soil. A community and ecosystem approach. Oxford University Press, New York.

Blanchet, F.G., Legendre, P., Borcard, D., 2008. Forward selection of explanatory variables. Ecology 89, 2623-2632.

Borcard, D., Legendre, P., Drapeau, P., 1992. Partialling out the spatial component of ecological variation. Ecology 73, 1045-1055.

Callaway, R.M., 1997. Positive interactions in plant communities and the individualistic-continuum concept. Oecologia 112, 143-149.

Callaway, R.M., Brooker, R.W., Choler, P., Kikvidze, Z., Lortie, C.J., Michalet, R., Paolini, L., Pugnaire, F.I., Newingham, B., Aschehoug, E.T., Armas, C., Kikodze, D., Cook, B.J., 2002. Positive interactions among alpine plants increase with stress. Nature $417,844-848$.

Caruso, T., Taormina, M., Migliorini, M., 2012. Relative role of deterministic and stochastic determinants of soil animal community: a spatially explicit analysis of oribatid mites. J Anim Ecol 81, 214-221.

Chu, C.J., Wang, Y.S., Du, G.Z., Maestre, F.T., Luo, Y.J., Wang, G., 2007. On the balance between niche and neutral processes as drivers of community structure along a successional gradient: Insights from alpine and sub-alpine meadow communities. Ann Bot-London 100, 807-812.

Dray, S., 2011. spacemakeR: Spatial modelling.

Dray, S., Legendre, P., Peres-Neto, P.R., 2006. Spatial modelling: a comprehensive framework for principal coordinate analysis of neighbour matrices (PCNM). Ecol Model 196, 483-493.

Eckhardt, H.C., vanRooyen, N., Bredenkamp, G.J., 1996. Species richness and plant communities of the Helichrysum rugulosum Hyparrhenia hirta low-altitude grassland of northern KwaZulu-Natal. S Afr J Bot 62, 296-305.

Google, I.L., 2013. Google Maps API Terms of Use.

Gotelli, N.J., 2000. Null model analysis of species co-occurrence patterns. Ecology 81, 2606-2621.

Gotelli, N.J., Entsminger, G.L., 2012. EcoSim 7.72. Acquired Intelligence, Inc.

Gotelli, N.J., Graves, G.R., Rahbek, C., 2010. Macroecological signals of species interactions in the Danish avifauna. Proc Natl Acad Sci U S A 107, 5030-5035.

Götzenberger, L., de Bello, F., Bråthen, K.A., Davison, J., Dubuis, A., Guisan, A., Lepš, J., Lindborg, R., Moora, M., Pärtel, M., Pellissier, L., Pottier, J., Vittoz, P., Zobel, K., Zobel, M., 2012. Ecological assembly rules in plant communities-approaches, patterns and prospects. Biol Rev 87, 111-127.

Gough, L., Shaver, G.R., Carroll, J., Royer, D.L., Laundre, J.A., 2000. Vascular plant species richness in Alaskan arctic tundra: the importance of soil pH. J Ecol 88, 54-66.

Hall, C.A., Chase, J.M., Leibold, M.A., 2003. Ecological niches: linking classical and contemporary approaches. University Of Chicago Press, Chicago, IL. 
Hensen, I., 1997. Life strategy systems of xerothermic grasslands - mechanisms of reproduction and colonization within Stipetum capillatae s.l. and Adonido - Brachypodietum pinnati. Feddes Repert 108, 28.

HilleRisLambers, J., Adler, P.B., Harpole, W.S., Levine, J.M., Mayfield, M.M., 2012. Rethinking Community Assembly through the Lens of Coexistence Theory. Annu Rev Ecol Evol Syst 43, 227-248. Hubbell, S.P., 2001. The unified neutral theory of biodiversity and biogeography. Princeton University Press, Princeton.

Jones, M.M., Tuomisto, H., Borcard, D., Legendre, P., Clark, D.B., Olivas, P.C., 2008. Explaining variation in tropical plant community composition: influence of environmental and spatial data quality. Oecologia 155, 593-604.

Khan, S.M., Page, S., Ahmad, H., Harper, D., 2013. Identifying plant species and communities across environmental gradients in the Western Himalayas: Method development and conservation use. Ecological Informatics 14, 99-103.

Klotz, S., Kühn, I., Durka, W., 2002. BIOLFLOR - Eine Datenbank mit biologisch-ökologischen Merkmalen zur Flora von Deutschland. Schriftenreihe für Vegetationskunde, Bonn.

Krömer, T., Acebey, A., Kluge, J., Kessler, M., 2013. Effects of altitude and climate in determining elevational plant species richness patterns: A case study from Los Tuxtlas, Mexico. Flora - Morphology, Distribution, Functional Ecology of Plants 208, 197-210.

Latimer, A.M., Jacobs, B.S., 2012. Quantifying how fine-grained environmental heterogeneity and genetic variation affect demography in an annual plant population. Oecologia 170, 659-667.

Legendre, P., 1993. Spatial autocorrelation - trouble or new paradigm. Ecology 74, 1659-1673. Legendre, P., Legendre, L., 1998. Numerical Ecology. Elsevier Science, Amsterdam.

Leibold, M.A., 1995. The niche concept revisited - mechanistic models and community context. Ecology 76, 1371-1382.

Leibold, M.A., Holyoak, M., Mouquet, N., Amarasekare, P., Chase, J.M., Hoopes, M.F., Holt, R.D., Shurin, J.B., Law, R., Tilman, D., Loreau, M., Gonzalez, A., 2004. The metacommunity concept: a framework for multi-scale community ecology. Ecol Lett 7, 601-613.

Li, Q., Yang, X., Soininen, J., Chu, C.J., Zhang, J.Q., Yu, K.L., Wang, G., 2011. Relative importance of spatial processes and environmental factors in shaping alpine meadow communities. J Plant Ecol-Uk 4, 249-258.

Ludewig, K., Korell, L., Löffler, F., Scholz, M., Mosner, E., Jensen, K., 2014. Vegetation patterns of floodplain meadows along the climatic gradient at the Middle Elbe River. Flora - Morphology, Distribution, Functional Ecology of Plants 209, 446-455.

Medinski, T.V., Mills, A.J., Esler, K.J., Schmiedel, U., Jurgens, N., 2010. Do soil properties constrain species richness? Insights from boundary line analysis across several biomes in south western Africa. J Arid Environ 74, 1052-1060.

Naaf, T., Wulf, M., 2012. Plant community assembly in temperate forests along gradients of soil fertility and disturbance. Acta Oecol 39, 101-108.

O'Neill, R.V., 1989. Perspectives in hierarchy and scale, in: May, R.M., Levin, S.A. (Eds.), Perspectives in Ecological Theory. Princeton University Press, Princeton, pp. 140-156.

Oksanen, J., Guillaume Blanchet, F., Kindt, R., Legendre, P., Minchin, P.R., O'Hara, R.B., Simpson, G.L., Solymos, P., Stevens, M.H.H., Wagner, H., 2012. vegan: Community ecology package.

Olff, H., Ritchie, M.E., 1998. Effects of herbivores on grassland plant diversity. Trends Ecol Evol 13, 261265.

Parfitt, R.L., Yeates, G.W., Ross, D.J., Schon, N.L., Mackay, A.D., Wardle, D.A., 2010. Effect of fertilizer, herbicide and grazing management of pastures on plant and soil communities. Appl Soil Ecol 45, 175186.

Payne, R.J., Stevens, C.J., Dise, N.B., Gowing, D.J., Pilkington, M.G., Phoenix, G.K., Emmett, B.A., Ashmore, M.R., 2011. Impacts of atmospheric pollution on the plant communities of British acid grasslands. Environ Pollut 159, 2602-2608.

Reitalu, T., Sykes, M.T., Johansson, L.J., Lönn, M., Hall, K., Vandewalle, M., Prentice, H.C., 2009. Smallscale plant species richness and evenness in semi-natural grasslands respond differently to habitat fragmentation. Biol Conserv 142, 899-908. 
Ristow, M., Rohner, M.-S., Heinken, T., 2011. Die Oderhänge bei Mallnow und Lebus, Tuexenia, pp. 127-144.

Rosindell, J., Hubbell, S.P., He, F., Harmon, L.J., Etienne, R.S., 2012. The case for ecological neutral theory. Trends Ecol Evol 27, 203-208.

Rossel, D., Taradellas, J., Bitton, G., Morel, J., 1997. Use of enzymes in soil ecotoxicology: A case for dehydrogenase and hydrolytic enzymes, in: Taradellas, J., Bitton, G., Rossel, D. (Eds.), Soil Ecotoxicology. CRC Press, pp. 179-206.

Sebastiá, M.-T., 2004. Role of topography and soils in grassland structuring at the landscape and community scales. Basic Appl Ecol 5, 331-346.

Shantz, H.L., 1954. The place of grasslands in the Earth's cover. Ecology 35, 3.

Silva, I.A., Batalha, M.A., 2010. Woody plant species co-occurrence in Brazilian savannas under different fire frequencies. Acta Oecol 36, 85-91.

Silva, I.A., Batalha, M.A., 2011. Plant functional types in Brazilian savannas: The niche partitioning between herbaceous and woody species. Perspect Plant Ecol Evol Syst 13, 201-206.

Soudzilovskaia, N.A., Graae, B.J., Douma, J.C., Grau, O., Milbau, A., Shevtsova, A., Wolters, L., Cornelissen, J.H.C., 2011. How do bryophytes govern generative recruitment of vascular plants? New Phytol 190, 1019-1031.

Sparks, D.L., 1996. Methods of soil analysis part 3: Chemical methods. American Society of Agronomy. Team, R.C., 2013. R: A language and environment for statistical computing. R Foundation for Statistical Computing, Vienna.

Thomas, S.M., Palmer, M.W., 2007. The montane grasslands of the Western Ghats, India: Community ecology and conservation. Community Ecol 8, 67-73.

Tilman, D., Olff, H., 1991. An experimental study of the effects of $\mathrm{pH}$ and nitrogen on grassland vegetation. Acta Oecol 12, 427-441.

Toogood, S.E., Joyce, C.B., Waite, S., 2008. Response of floodplain grassland plant communities to altered water regimes. Plant Ecol 197, 285-298.

Turner, M.G., O’Neill, R.V., 1995. Exploring aggregation in space and time, in: Jones, C., Lawton, J.H. (Eds.), Linking Species and Ecosystems. Chapman \& Hall, New York, pp. 194-208.

Turtureanu, P.D., Palpurina, S., Becker, T., Dolnik, C., Ruprecht, E., Sutcliffe, L.M.E., Szabó, A., Dengler, J., 2013. Scale- and taxon-dependent biodiversity patterns of dry grassland vegetation in Transylvania (Romania). Agric Ecosyst Environ http://dx.doi.org/10.1016/j.agee.2013.10.028.

Ulrich, W., 2008. Pairs - a FORTRAN program for studying pair-wise species associations in ecological matrices.

Ulrich, W., Gotelli, N.J., 2007. Null model analysis of species nestedness patterns. Ecology 88, 18241831.

van Lierop, W., Mackenzie, A.F., 1977. Soil-pH measurement and its application to organic soils. Can J Soil Sci 57, 55-64.

Walker, L.R., Chapin, F.S., 1987. Interactions among processes controlling successional change. Oikos 50, 131-135.

Wellstein, C., Otte, A., Waldhardt, R., 2007. Impact of site and management on the diversity of central European mesic grassland. Agric Ecosyst Environ 122, 203-210.

Wiegand, T., Huth, A., Getzin, S., Wang, X., Hao, Z., Gunatilleke, C.V., Gunatilleke, I.A., 2012. Testing the independent species' arrangement assertion made by theories of stochastic geometry of biodiversity. Proc R Soc Lond B Biol Sci. 
581 Figure 1: Sampling location and sampling design: all three macroplots were located on a hill 582 slope in a German natural reserve close to the Polish border, offering a high environmental 583 gradient within a few meters. A: A general map of Germany with the sampling area as red 584 rectangle (left) and a satellite picture of the sampling area (right) (Google, 2013). Purple 585 rectangles labelled as P1, P2 and P3 depict the location and orientation of the three macroplots. 586 B: Diagrams of the three macroplots. The spatial gradient is oriented orthogonally to the 587 environmental gradient. From the four corner plots (green), five F. brevipila plants were 588 sampled randomly as described in the materials and methods section (black dots). Numbers on 589 the diagrams represent the size of the respective macroplots in metres. 
591 Table 1: P-Values of the RDA (redundancy analysis) based permutation tests and 592 decomposition of the total variation in the community matrix into unique environmental (soil 593 properties) and spatial (geographic position) components. Significant values are bold. 594 Important variables were selected by applying automatic stepwise model building for 595 constrained ordination methods including forward and backward selection. Values in italic were 596 dismissed in the step-wise selection process from the model. The last line ("explained 597 variation”) shows the percentage of explained variation of each component. The amount of 598 unexplained variation was 62.9\%. P-values for the environmental variables in the column "env" 599 are based on partial-RDA, which accounts for spatial autocorrelation. P-values for the same 600 variables but in the column "space + env." are based on the RDA that does not correct for spatial 601 autocorrelation, which can therefore include spatially structured environmental effects. Missing 602 values marked with a "-" are non-testable.

603 604

\begin{tabular}{cccc}
\hline component & env. & space + env. & space \\
\hline Carbon & 0.48 & $\mathbf{0 . 0 1}$ & - \\
Nitrogen & 0.06 & $\mathbf{0 . 0 5}$ & - \\
C/N ratio & 0.85 & 0.21 & - \\
Phosphorus & 0.07 & $\mathbf{0 . 0 1}$ & - \\
pH & $\mathbf{0 . 0 1}$ & $\mathbf{0 . 0 1}$ & - \\
microbial activity & $\mathbf{0 . 0 4}$ & $\mathbf{0 . 0 2}$ & - \\
water content & 0.51 & 0.64 & - \\
cumulative & $<\mathbf{0 . 0 1}$ & - & $<\mathbf{0 . 0 1}$ \\
\hline explained variation & $17.9 \%$ & $4.7 \%$ & $14.5 \%$ \\
\hline
\end{tabular}

605 
607 Table 2: Null model analysis of community variation, using the C-Score index and the 608 algorithm MOD9 in PAIRS as described by Ulrich \& Gotelli (Gotelli and Entsminger, 2012; 609 2007). The effect sizes and P-values of different subdivisions of the plant community matrix 610 are shown. Positive effect sizes implies a segregating community (species repel each other), 611 negative values indicate an aggregating one (species attract each other). P-Values are depicted 612 as stars: $*=\mathrm{P}<0.05 ; * *=\mathrm{P}<0.01 ; * * *=\mathrm{P}<0.001$; $\mathrm{NS}=$ not significant. The left table represents 613 heterogeneous subsets used for inferences on community composition, while the right table 614 represents homogenous subsets used to check the validity of our heterogeneous subset 615 assumptions.

616

\begin{tabular}{ccc}
\hline community matrix & $\begin{array}{c}\text { effect } \\
\text { size }\end{array}$ & $\mathrm{P}$ \\
\hline all plots & 7.25 & $* * *$ \\
top plots & 5.48 & $* * *$ \\
bottom plots & 3.24 & $* *$ \\
left plots & 2.24 & $*$ \\
right plots & 8.04 & $* * *$ \\
\hline macroplot 1 & 6.40 & $* * *$ \\
macroplot 2 & 2.75 & $*$ \\
macroplot 3 & 6.18 & $* * *$ \\
\hline diagonal with gradient & 6.49 & $* * *$ \\
diagonal w/o gradient & 3.31 & $* *$ \\
\hline
\end{tabular}

\begin{tabular}{ccc}
\hline community matrix & $\begin{array}{c}\text { effect } \\
\text { size }\end{array}$ & P \\
\hline macroplot 1 left & 3.53 & $* *$ \\
macroplot 2 left & 1.85 & NS \\
macroplot 3 left & 4.41 & $* *$ \\
macroplot 1 right & 5.54 & $* * *$ \\
macroplot 2 right & 1.55 & NS \\
macroplot 3 right & -1.03 & NS \\
\hline plot 1 & -1.19 & $*$ \\
plot 2 & 0.16 & NS \\
plot 3 & 0.71 & NS \\
plot 4 & 0.77 & NS \\
plot 5 & 3.51 & $* *$ \\
plot 6 & 1.15 & NS \\
plot 7 & 1.14 & NS \\
plot 8 & 0.66 & NS \\
plot 9 & -0.37 & NS \\
plot 10 & 0.00 & NS \\
plot 11 & -0.15 & NS \\
plot 12 & -0.58 & NS \\
\hline
\end{tabular}

